\title{
Şimdilerde Şehir: Hayal Kırıklığı
}

\section{Murat Germen*}

İstanbul'da yürütülen kentsel dönüşüm hamlesinin en ağır hasar verdiği yerleşim bölgesi Fikirtepe. Murat Germen, 2014.

Levent'te, 2010 yilında açılan ve Avrupa'nın en yüksek gökdelenlerinden

Sapphire'in Kağıthane yönünden alçak katlı eski yapı stoku ile birlikte görüntüsü. Murat Germen, 2014.
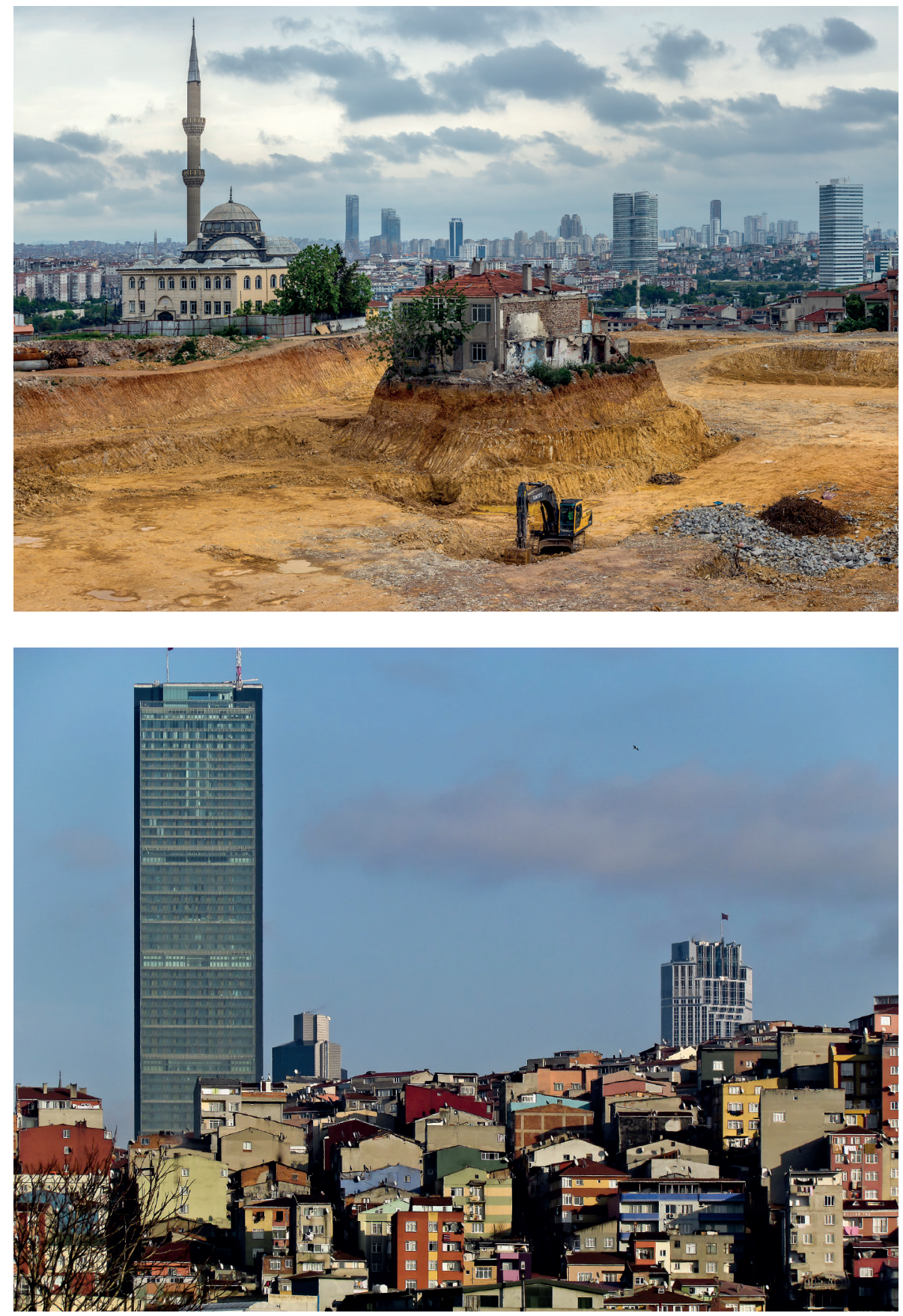

*Sabancı Üniversitesi, muratgermen@sabanciuniv.edu 


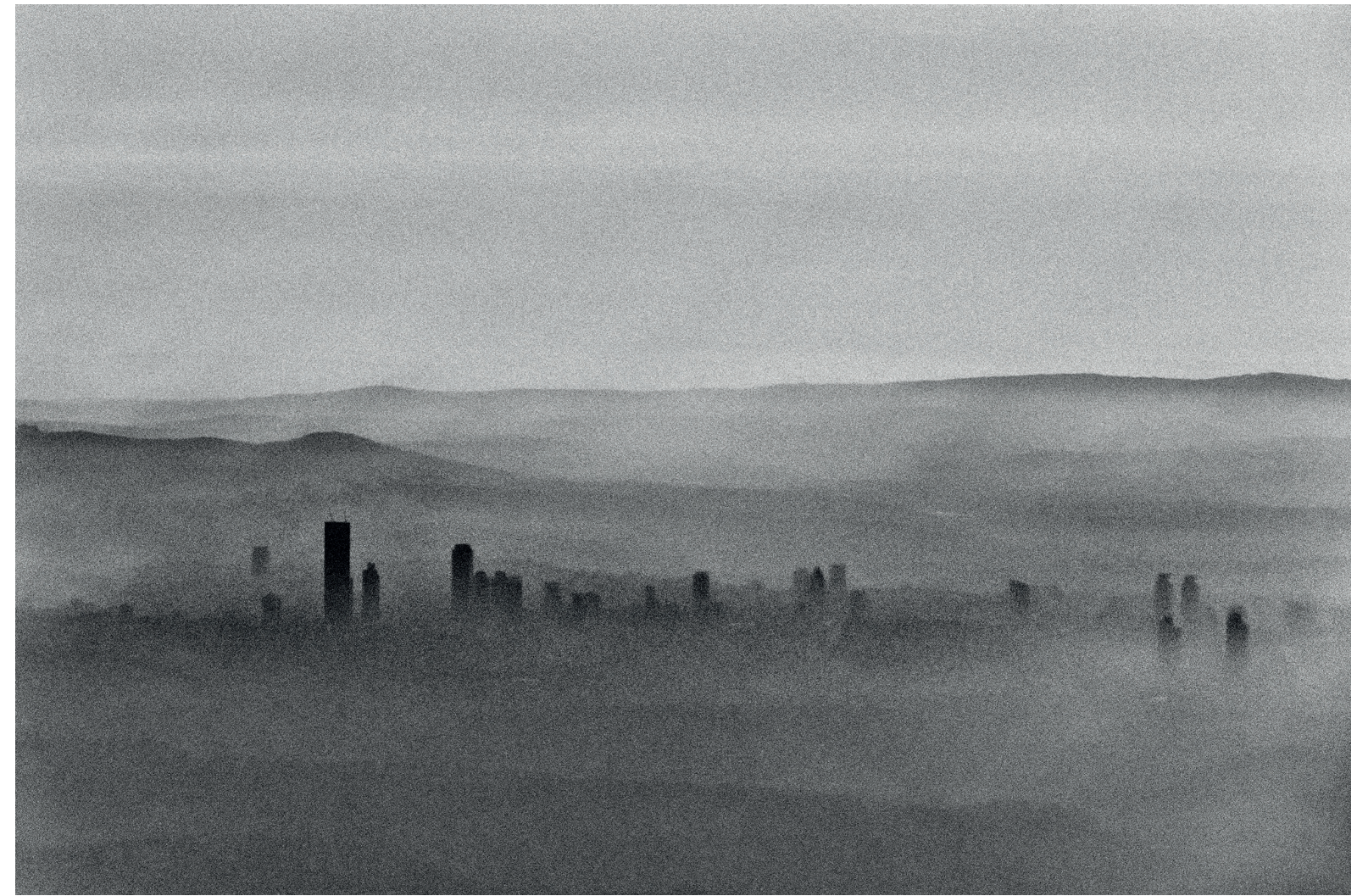

Yoğun yapılaşmanın ve pahalı doğalgazın ucuz alternatifi kötü kalite kömür kullanımının yol açıı̆̆ı hava kirlilïği sisi. Levent bölgesi gökdelenleri, sisin içinden, uçaktan görünüyor.

Istanbul'un son kalan akciğerleri olan Kuzey Ormanları’na çok derin bir yara açmış, 1. ve 2. köprülerdeki trafik skkışıklı̆̆ı̆ıı hiçbir şekilde hafiffletememiş olan; aynı Osmangazi (Körfez) Köpriüsü’ndeki gibi yüksek ücretinden kaynaklanan çok düs̆̈̈̈k yoğunluklu araç geçişi dolayısıyla neden inşa edildiğini henüz anlayamadı̆̆ımız Yavuz Sultan Selim Köprüsü inşa edilirken.
Murat Germen, 2014.

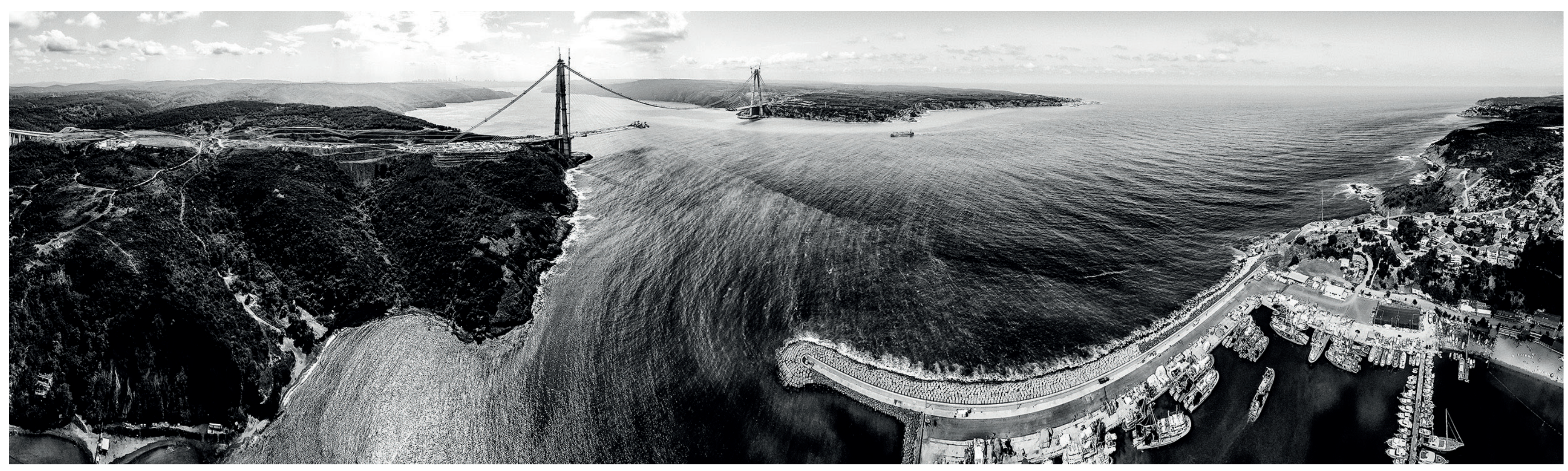




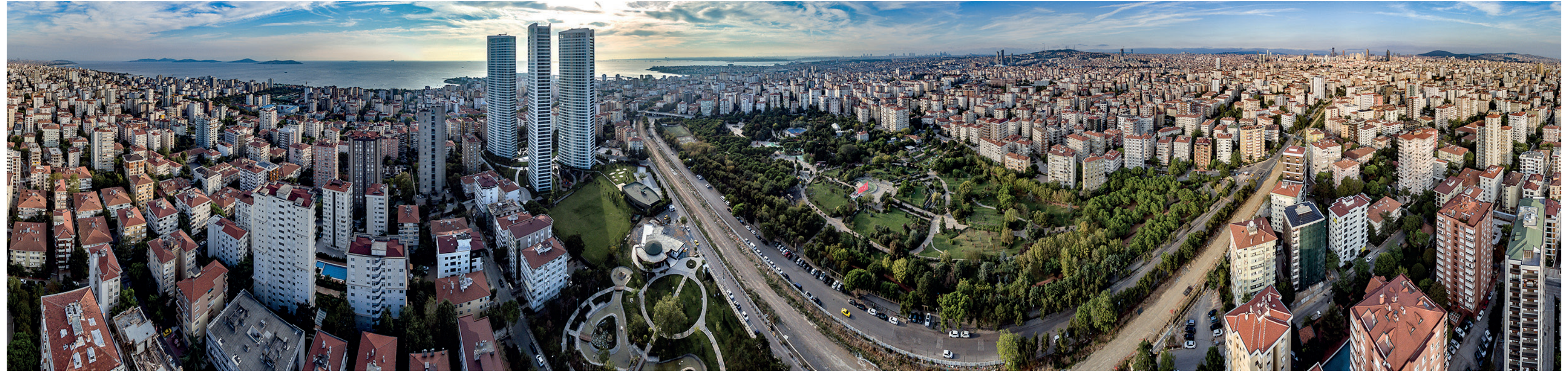

Çevresinde hiçbir kat yüksekliği emsali olmamasından dolayı istanbul'daki en büyük kent suçu olarak gördüğŭm, yesillikik içerisindeki Meteoroloji Genel Müdürlüŭğ arsasına yerlesememiş, sağğndaki üçü aksamlarr zifiri karanlık, yani daireler bos ; dördüncüsünnde ise toplasanan z yirmi-otuz dairenin ısı̆ğ yanıyor. Bu durum en az dört-bes senedir böyle; hemen yakınlarında bir apartmanda yașadıs̆ı için her akşam karşımda bu karanlık heyulaları gözlemlemek zorundayım.

Murat Germen, 2014.

Türkiye'deki önemli Körfez sermayesi yatrirmcllarından biri olan Emaar Square Residences adll lüks gayrimenkul ve AVM projesi inșaat halinde. Murat Germen, 2014.

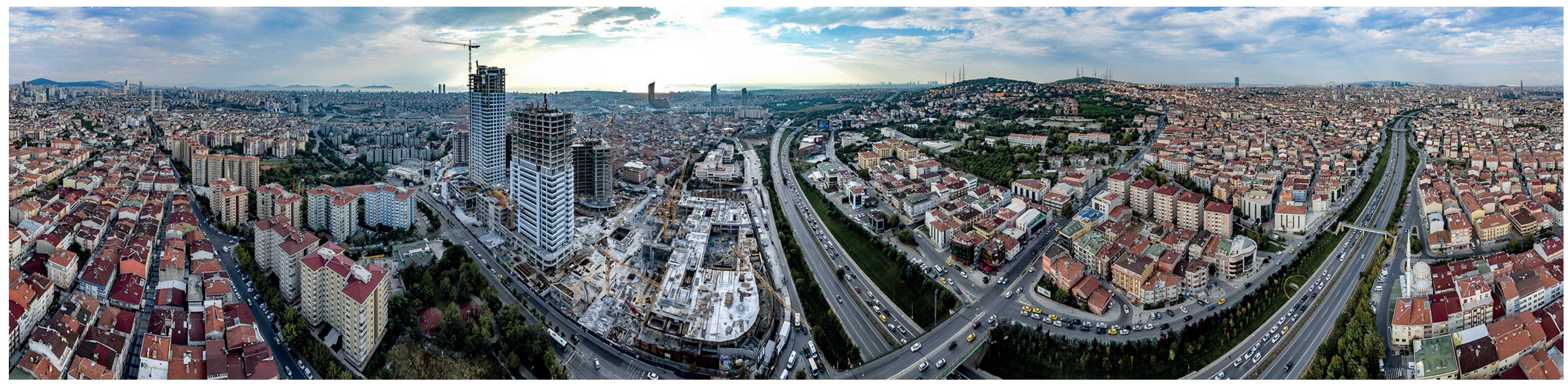


162

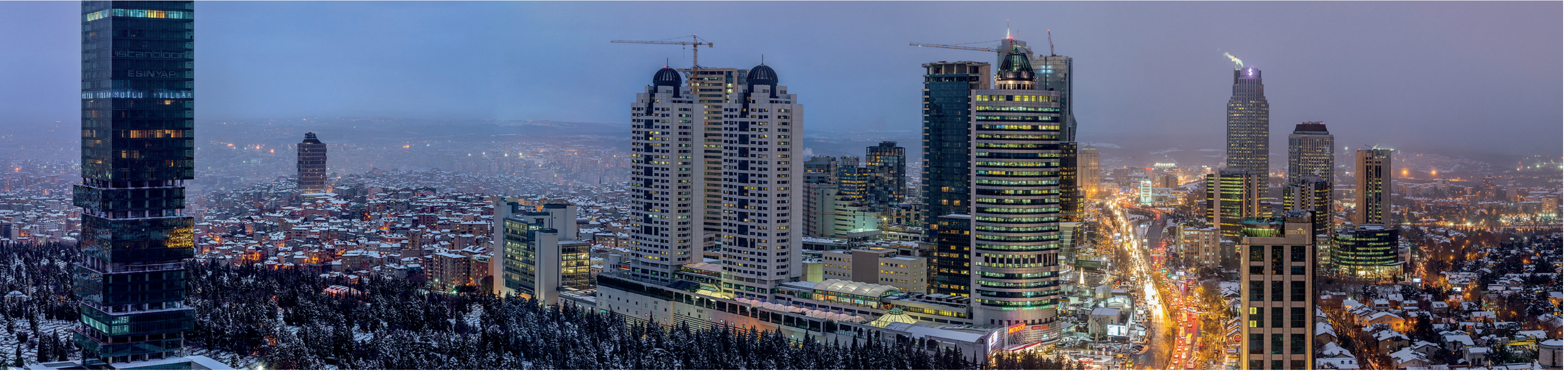

Zincirlikuyu-Levent hattında yer alan iş merkezleri bölgesindeki yoğun yüksek katlı yapılaşma ve

araya sıkışmış Zincirlikuyu Mezarlığ'nın ağaçları. Mezarlık olmasa bu bölgede ağaç ya da yeșild

bahsedemeyecektik.
Murat Germen, 2014.

“istanbul'un yeni kara surlarr” olarak tanımladı̆ı̆m ve aralıksız yüksek yapılaşmanın en yoğun olduğu bölgelerden birisi olan Atasehir.
Murat Germen, 2014.

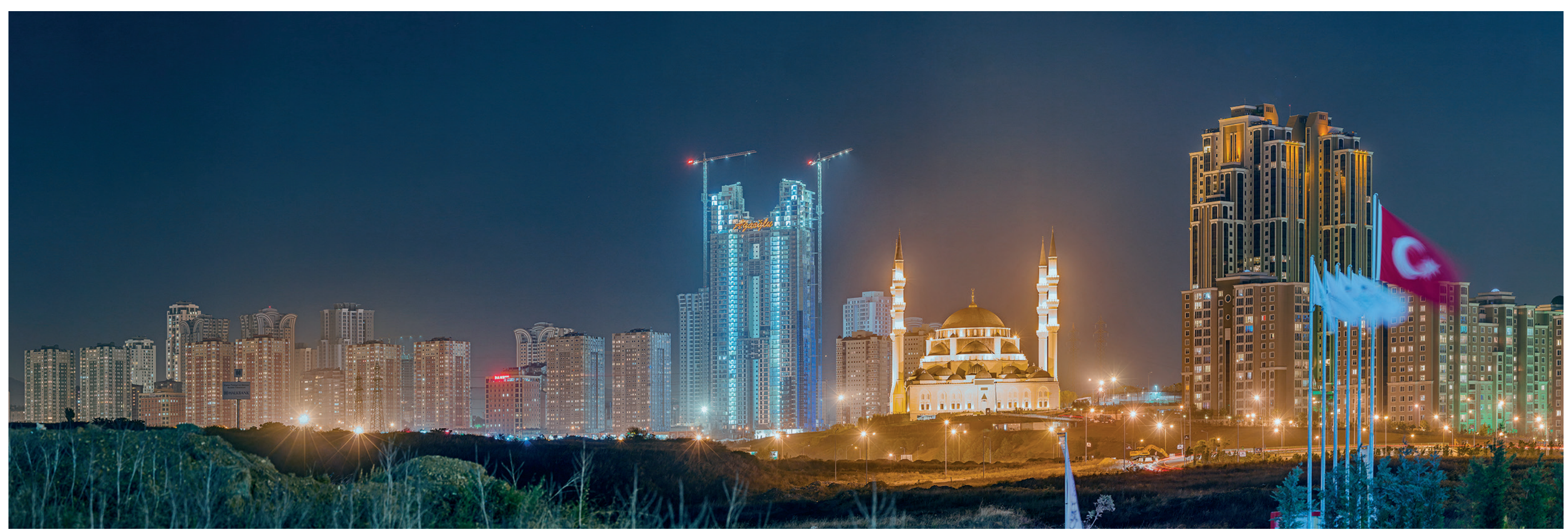

